\title{
Frequency-specific hypoglycemic effects of microwave irradiation on normal and streptozotocin-induced diabetic rats
}

\author{
Jong-Sam Ryo, Gye-Ryong Jo, Gyong-Song Kim, Jong-Ae Ri \\ Pyongyang Medical College, Kim Il Sung University, Pyongyang, Democratic People's Republic of Korea \\ Contributions: (I) Conception and design: JS Ryo, GR Jo; (II) Administrative support: GS Kim, JA Ri; (III) Provision of study materials: JA Ri; (IV) \\ Collection and assembly of data: GS Kim, JA Ri; (V) Data analysis and interpretation: JS Ryo, GR Jo; (VI) Manuscript writing: All Authors; (VII) \\ Final approval of manuscript: All Authors. \\ Correspondence to: Jong-Sam Ryo. Pyongyang Medical College, Kim Il Sung University, Pyongyang, Democratic People’s Republic of Korea. \\ Email: pmed4@ryongnamsan.edu.kp.
}

\begin{abstract}
Background: Treatment for diabetes is traditionally performed using subcutaneous insulin injection and oral anti-diabetic agents, especially plant-derived hypoglycemic agents. Besides, bioresonance therapy or biophysical information therapy is also performed for diabetes and other disorders as a form of complementary medical method. This study aimed to explore a specific hypoglycemic frequency of human insulin in microwave band and to assess the effects of irradiation of microwave at the frequency on blood glucose (BG) levels in normal and diabetic rats.

Methods: One hundred and ninety-five normal and 25 diabetic Wistar rats were used in this experiment. Among peak frequencies obtained from frequency-intensity curve of human insulin solution by using Network Analyzer, a hypoglycemic frequency was identified by measurements of BG levels after irradiation of microwave in $18 \mathrm{~h}$ fasted normal rats. BG and serum insulin levels in normal and diabetic rats, and $\alpha$-Dglucose concentration were determined after irradiation of microwave at the frequency.

Results: Among six peak frequencies obtained from frequency-intensity curve of insulin solution, only 15.37 $\mathrm{GHz}$ could exert the ability to decrease fasting blood glucose (FBG) level and glucose tolerance in normal rats, especially, $15.370 \mathrm{GHz}$ showed the highest effect. Whole-body irradiation of microwave at the frequency with intensities of 0.1 to $10 \mathrm{~mW} / \mathrm{cm}^{2}$ for 1 hour lowered FBG and BG levels after glucose loading in normal and diabetic rats, and showed no changes in fasting serum insulin levels in normal and diabetic rats.
\end{abstract}

Conclusions: Irradiation of $15.370 \mathrm{GHz}$ microwave lowers BG level in normal and diabetic rats just like insulin.

\begin{abstract}
Keywords: Diabetes mellitus; streptozotocin-induced diabetic rat (STZ-induced diabetic rat); blood glucose (BG); serum insulin; bioresonance; microwave irradiation
\end{abstract}

Received: 27 January 2020; Accepted: 13 November 2020; Published: 30 April 2021.

doi: $10.21037 /$ ht-20-7

View this article at: http://dx.doi.org/10.21037/ht-20-7

\section{Introduction}

Diabetes mellitus is a serious chronic metabolic disturbance which is characterized by obstinate elevation of blood glucose (BG) levels caused by inadequate insulin secretion and/or a peripheral resistance to insulin action (1).

Treatment for diabetes is traditionally performed using oral anti-diabetic agents and subcutaneous insulin injection (2). Drug therapy for diabetes, however, is connected with adverse effects related to pharmacokinetic characteristics, hypoglycemia, secondary failures, skin reactions, gastrointestinal disturbances, rise in hepatic enzyme level and hematological disorders (1). Plantderived hypoglycemic agents are a significant alternative treatment for diabetes. For thousands of years, plant extracts have been widely used for treatment of diabetes as a complementary therapy (2-5). 
As a form of complementary medical method, bioresonance therapy or biophysical information therapy has been performed for diabetes and other disorders. This has been effectively applied by a number of practitioners worldwide oriented to scientific healing for 40 years. There are numerous pieces of positive evidence of individual cases concerning various indications, for instance, allergies such as asthma, hay fever, food hypersensitivity and atopic eczema, functional gastrointestinal complaints, metabolic disorders, spontaneous abortion, rheumatic forms and psychosomatic illnesses (6-8). Low-frequency, high-frequency and microwave bioresonance therapies or hypotheses were studied in a variety of experimental models and patients with different diseases (9-12). Diabetic patients have human individual characteristic frequency (ICF) of 58.4 and $60.8 \mathrm{GHz}$ for type 1 and 2 respectively, and the electromagnetic irradiation of low intensity below $10 \mathrm{~mW} / \mathrm{cm}^{2}$ has therapeutic effects by correcting ICF of a patient (13).

However, there are limited studies on the hypoglycemic effects of microwave which has the pharmacological information of anti-diabetic drugs on living organisms. Hence, the aim of this study was to explore the specific hypoglycemic frequency of insulin in microwave band and to assess the effects of microwave irradiation at the frequency on normoglycemia in normal rats and hyperglycemia in streptozotocin (STZ)-induced diabetic rats. We present the following article in accordance with the ARRIVE reporting checklist (available at http://dx.doi. org/10.21037/ht-20-7).

\section{Methods}

\section{Experimental animals}

Healthy adult male Wistar rats weighing 190-230 g were obtained from the Laboratory Animal House of Pyongyang Medical College. Experiments were performed under a project license (No. 1354822) granted by the University ethics board of the Pyongyang Medical College, in compliance with the University guidelines for the care and use of animals. All rats were kept under observation for about a week prior to the commencement of the experiment. The animals were housed five animals per cage and allowed free access to water and pelleted standard diet. They were maintained under standard laboratory conditions (temperature of $22-24{ }^{\circ} \mathrm{C}$, humidity of $45-55 \%$, and $12 \mathrm{~h}$ light/dark cycles).

\section{Chemicals}

The recombinant human insulin (Insulin Human Powder, I0259, Sigma, USA) expressed in E. coli was used for exploration of the hypoglycemic frequency. STZ and $\alpha-\mathrm{D}-$ glucose were products of Sigma Chemicals (St. Louis, MO, USA). Insulin reagent sets used to measure the serum insulin levels were purchased from Roche Diagnostics (Mannheim, Germany). All other chemicals and solvents were of analytical grades.

\section{Experimental design}

A total of 220 mature adult male Wistar rats were used in the present study. They comprised of 195 normal and 25 diabetic rats and were randomly divided into 44 groups (35 experimental and 9 control groups) with five rats in each group as follows; 4 normal control groups (Group NC) and 1 diabetic control group (Group DC) nonirradiated with microwaves, 17 normal groups (Group N $+M W$ ) and 2 diabetic groups (Group D + MW) irradiated with microwaves, 3 normal control groups (Group NC + GL) and one diabetic control group (Group DC+GL) loaded with glucose, and, 15 normal groups (Group N + $\mathrm{GL}+\mathrm{MW}$ ) and 1 diabetic group (Group D + GL + MW) irradiated with microwaves immediately after glucose loading. Fasting blood glucose (FBG) or BG levels were determined on rats in 3 Groups of NC, 16 Groups of $\mathrm{N}+$ MW, 3 Groups of NC + GL, 15 Groups of $\mathrm{N}+\mathrm{GL}+\mathrm{MW}$, 1 Group of D + MW, 1 Group of DC + GL and 1 Group of D + GL + MW. Serum glucose and insulin levels were measured on rats in each Group of NC, N + MW, DC and $\mathrm{D}+\mathrm{MW}$, respectively.

\section{Induction of experimental diabetes}

Experimental diabetes was induced by a single intraperitoneal injection of $55 \mathrm{mg} / \mathrm{kg}$ body weight of STZ $(0.2 \mathrm{~g}$ dissolved in $10 \mathrm{~mL}$ of fresh $0.1 \mathrm{~mol} / \mathrm{L}$ cold sodium citrate buffer of $\mathrm{pH} 4.5$ ) into $18 \mathrm{~h}$ fasted rats (14). The same dosage of sodium citrate buffer was injected intraperitoneally to the non-diabetic normal rats at $18 \mathrm{~h}$ fasted state for measurement of both serum glucose and insulin levels. After $6 \mathrm{~h}$ of STZ injection, the STZ-treated rats were given with $5 \%$ dextrose solution for the next $24 \mathrm{~h}$ to prevent fatal hypoglycemia as a result of massive pancreatic release of insulin (15). After 3 days of STZ 
injection, blood samples were taken from tail vein of STZtreated rats after overnight fasting and the rats with FBG levels $>230 \mathrm{mg} / \mathrm{dL}$ were considered diabetic. After 7 days of STZ injection the diabetic rats were included in the present study.

\section{Determination of BG and serum insulin levels}

The tails of rats were washed with $70 \%$ alcohol solution and blood samples were collected from the tail vein to determine the BG levels. The levels were determined immediately after collecting blood samples according to the glucoseoxidase principle (16), using the digital glucometer (AccuCheck Advantage, Roche Diagnostics, Germany), and were expressed as mg/dL (17). Furthermore, blood samples were withdrawn cleverly from the orbital plexus of rats under light ether anesthesia. The samples in non-anticoagulant tubes were left for 30 minutes at room temperature and then were centrifuged at 3,000 rpm for 15 minutes using centrifuge (5415C, Eppendorf, Germany), after which the supernatants were obtained and used for the determination of both serum glucose and insulin levels. Insulin levels in serum samples were measured by electrochemiluminescence immunoassay method developed by Roche Diagnostics (Mannheim, Germany), and were recorded as $\mu \mathrm{U} / \mathrm{mL}$ (18). The automated Elecsys insulin immunoassay was performed on the Elecsys 2010 analyzer according to the manufacturer's instructions.

\section{Oral glucose tolerance test}

Blood samples were obtained from tail vein of $18 \mathrm{~h}$ fasted rats to determine the FBG levels. Forty percent of glucose solution in a dose of $3 \mathrm{~g} / \mathrm{kg}$ body weight was then given orally by gastric intubation (19). Blood samples were withdrawn from tail of rats again $2 \mathrm{~h}$ after glucose loading and BG levels were determined.

\section{Exploration of the hypoglycemic frequency in microwave band}

Frequency-intensity curve of insulin solution was obtained by using Network Analyzer (Agilent 83623S, USA). The analyzer gets the curve by radiating the electromagnetic waves at the identical power density in microwave band $(<30 \mathrm{GHz})$ and also receiving the waves transmitted through the material to be tested, while minutely increasing or decreasing the frequencies in an automatic fashion. The insulin solution was made by dissolving $105 \mathrm{mg}$ of human insulin powder in $30 \mathrm{~mL}$ of $10 \mathrm{mmol} / \mathrm{L} \mathrm{HCl}$ at room temperature. Then the solution was filled into the resonant tube between radiating and receiving antennas, and the frequency-intensity curve was obtained as mentioned above. The experiment was performed in an electromagnetically shielded darkroom. Peaks of the curve were identified. Polyethylene cages were used for microwave irradiation on rats. FBG levels of normal rats were measured before the microwave radiation, then the whole-body irradiation was performed with the intensity of $0.1 \mathrm{~mW} / \mathrm{cm}^{2}$ for 1 hour at one of the peak frequencies, and finally, FBG levels $2 \mathrm{~h}$ after the commencement of irradiation or BG levels $2 \mathrm{~h}$ after glucose loading were measured. All peak frequencies were tried with the same method to find out the hypoglycemic frequency. Hypoglycemic effect on FBG levels and levels $2 \mathrm{~h}$ after glucose loading at the found frequency was further evaluated by varying the intensity of the irradiated microwave (i.e., 0.01, $0.1,1.0$ or $\left.10 \mathrm{~mW} / \mathrm{cm}^{2}\right)(13)$.

\section{Effect of the bypoglycemic frequency on glucose and insulin levels}

Ninety $\mathrm{mg} / \mathrm{dL} \alpha$-D-glucose solution was made and the levels were measured with glucometer. The solution was put on the polyethylene dish (height $1 \mathrm{~cm}$, diameter $8 \mathrm{~cm}$ ) and irradiated with intensity of $0.1 \mathrm{~mW} / \mathrm{cm}^{2}$ for 1 hour at the hypoglycemic frequency, and the glucose levels were measured $2 \mathrm{~h}$ after the commencement to compare with levels before the irradiation. Under the same method, the effects of microwave irradiation at the hypoglycemic frequency were evaluated on fasting serum glucose levels and fasting insulin levels in normal and diabetic rats, and on the BG levels after glucose loading in diabetic rats.

\section{Statistical analysis}

Data obtained from each group were expressed as the mean \pm SE. All statistical analysis was evaluated using SPSS version 16.0 software. Paired-samples or independent samples $t$-test was used to compare the differences between groups' means. $\mathrm{P}$ value of less than 0.05 was considered statistically significant.

\section{Results}

Peak frequencies in the frequency-intensity curve of human 
Table 1 FBG levels of normal rats irradiated with microwaves at peak frequencies

\begin{tabular}{|c|c|c|c|}
\hline Groups & Irradiation frequency $(\mathrm{GHz})$ & Before irradiation $(\mathrm{mg} / \mathrm{dL})$ & $2 \mathrm{~h}$ after irradiation $(\mathrm{mg} / \mathrm{dL})$ \\
\hline \multirow[t]{5}{*}{$N+M W$} & 10.53 & $92.2 \pm 2.7$ & $91.3 \pm 3.1$ \\
\hline & 13.17 & $93.2 \pm 3.8$ & $90.6 \pm 3.0$ \\
\hline & 13.82 & $91.8 \pm 3.7$ & $89.6 \pm 3.8$ \\
\hline & 16.03 & $90.8 \pm 3.8$ & $92.5 \pm 3.3$ \\
\hline & 17.35 & $89.2 \pm 3.8$ & $91.6 \pm 3.5$ \\
\hline
\end{tabular}

Values were expressed as mean \pm SE $(n=5) .{ }^{*}, P<0.01$ vs. level before irradiation. FBG, fasting blood glucose.

Table 2 BG levels after glucose loading of normal rats irradiated with microwaves at peak frequencies

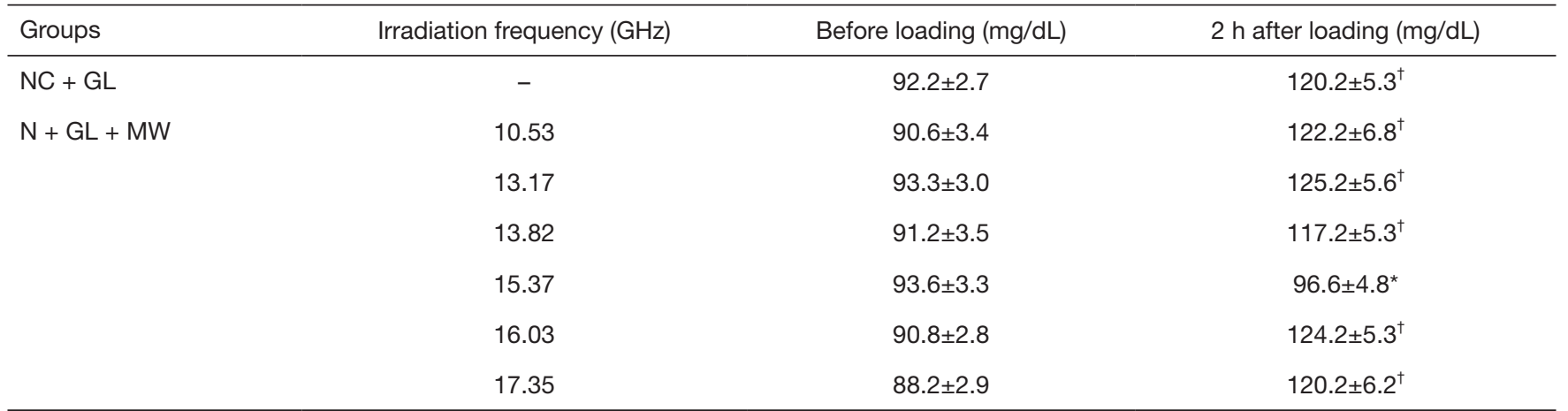

Values were expressed as mean $\pm \mathrm{SE}(\mathrm{n}=5) .{ }^{*}, \mathrm{P}<0.01$ vs. $\mathrm{NC}+\mathrm{GL} ;{ }^{\dagger}, \mathrm{P}<0.01$ vs. levels before loading. BG, blood glucose.

insulin, obtained with Network Analyzer were 10.53, 13.17, $13.82,15.37,16.03$ and $17.35 \mathrm{GHz}$. In normal rats, FBG level $2 \mathrm{~h}$ after the commencement of irradiation was shown to be significantly $(\mathrm{P}<0.01)$ decreased only in Group $\mathrm{N}+$ MW irradiated at $15.37 \mathrm{GHz}$ compared to the level before irradiation (see Table 1).

In Group NC + GL, to which only glucose loading had been applied, BG level $2 \mathrm{~h}$ after loading was shown to increase compared to that before loading. The BG level $2 \mathrm{~h}$ after loading was shown to be significantly $(\mathrm{P}<0.01)$ decreased almost to that before loading only in Group NC $+\mathrm{GL}+\mathrm{MW}$ irradiated at $15.37 \mathrm{GHz}$ compared to that of Group NC + GL, and it showed no significant difference compared to the level before loading. In other groups BG levels $2 \mathrm{~h}$ after loading showed no significant differences compared to that of Group NC + GL, but were significantly $(\mathrm{P}<0.01)$ increased compared to the levels before loading (see Table 2).

Therefore, it was demonstrated that only microwave at $15.37 \mathrm{GHz}$ was able to exert the hypoglycemic effect. However, it could be assumed that there might be more effective frequency around $15.37 \mathrm{GHz}$. To dispel such a suspicion, we varied the frequencies at intervals of 0.002 around $15.37 \mathrm{GHz}$ (in the range of 15.366 to $15.374 \mathrm{GHz}$ ), observing their effects on FBG levels and BG levels $2 \mathrm{~h}$ after loading. FBG levels $2 \mathrm{~h}$ after irradiation in Groups of $\mathrm{N}+\mathrm{MW}$ and BG levels $2 \mathrm{~h}$ after loading in Groups of $\mathrm{N}$ + GL + MW were shown to be the lowest at $15.370 \mathrm{GHz}$, followed by $15.372,15.368,15.366$ and $15.374 \mathrm{GHz}$. All the results so far suggest that irradiation of $15.370 \mathrm{GHz}$ microwave could exert the highest hypoglycemic effect.

At the frequency of $15.370 \mathrm{GHz}$, we tested the hypoglycemic effects on normal rats irradiated with microwaves of low intensities less than $10 \mathrm{~mW} / \mathrm{cm}^{2}$. Compared to FBG levels before irradiation, $0.01 \mathrm{~mW} / \mathrm{cm}^{2}$ microwave showed no significant change in those $2 \mathrm{~h}$ after irradiation. FBG levels $2 \mathrm{~h}$ after irradiation with microwaves of $0.1,1$ and $10 \mathrm{~mW} / \mathrm{cm}^{2}$ of intensity significantly $(\mathrm{P}<0.01)$ 
Table 3 Fasting serum glucose and insulin levels in normal and diabetic rats irradiated with $15.370 \mathrm{GHz}$ microwaves

\begin{tabular}{|c|c|c|c|c|}
\hline Groups & \multicolumn{2}{|c|}{ Fasting serum glucose level (mg/mL) } & \multicolumn{2}{|c|}{ Fasting serum insulin level ( $\mu \mathrm{U} / \mathrm{mL})$} \\
\hline NC & $92.6 \pm 2.9$ & $93.7 \pm 3.1$ & $11.2 \pm 1.2$ & $10.8 \pm 1.3$ \\
\hline $\mathrm{N}+\mathrm{MW}$ & $95.5 \pm 3.1$ & $77.5 \pm 3.3^{\star \S}$ & $10.0 \pm 1.4$ & $11.3 \pm 1.2$ \\
\hline DC & $281.7 \pm 16.5^{\dagger}$ & $288.2 \pm 18.6^{\dagger}$ & $3.5 \pm 0.3^{\dagger}$ & $3.3 \pm 0.4^{\dagger}$ \\
\hline
\end{tabular}

Values were expressed as mean $\pm \mathrm{SE}(\mathrm{n}=5) .{ }^{*}, \mathrm{P}<0.05$ for $\mathrm{N}+\mathrm{MW}$ vs. $\mathrm{NC} ;{ }^{\dagger}, \mathrm{P}<0.01$ for $\mathrm{DC}$ vs. $\mathrm{NC} ;{ }^{\natural}, \mathrm{P}<0.05$ for $\mathrm{D}+\mathrm{MW}$ vs. $\mathrm{DC} ;{ }^{\S}, \mathrm{P}<0.05$ vs. levels before irradiation.

Table 4 BG levels after glucose loading in diabetic rats irradiated with $15.370 \mathrm{GHz}$ microwaves

\begin{tabular}{lcc}
\hline Groups & Before loading $(\mathrm{mg} / \mathrm{dL})$ & $2 \mathrm{~h}$ after loading $(\mathrm{mg} / \mathrm{dL})$ \\
\hline $\mathrm{DC}+\mathrm{GL}$ & $288.2 \pm 17.8$ & $423.4 \pm 26.6^{\natural}$ \\
$\mathrm{D}+\mathrm{GL}+\mathrm{MW}$ & $283.6 \pm 14.7$ & $338.4 \pm 19.3^{\star \dagger}$ \\
\hline
\end{tabular}

Values were expressed as mean $\pm \mathrm{SE}(\mathrm{n}=5) .{ }^{*}, \mathrm{P}<0.05$ vs. $\mathrm{DC}+\mathrm{GL} ;{ }^{\dagger}, \mathrm{P}<0.05$ vs. levels before loading; ${ }^{\natural}, \mathrm{P}<0.01$ vs. levels before loading. $B G$, blood glucose.

decreased, while significant differences were not found between them. In the group irradiated with $0.01 \mathrm{~mW} / \mathrm{cm}^{2}$ microwaves, BG level $2 \mathrm{~h}$ after loading was significantly $(\mathrm{P}<0.01)$ higher than that before loading and not significantly different from Group NC + GL. At intensities of 0.1 to $10 \mathrm{~mW} / \mathrm{cm}^{2}$, however, the level $2 \mathrm{~h}$ after loading was lower than that of Group NC + GL, being close to that before loading.

When $90 \mathrm{mg} / \mathrm{dL}$ glucose solution was irradiated with 15.370 GHz microwave, its concentrations were 88.5$91.3 \mathrm{mg} / \mathrm{dL} 2 \mathrm{~h}$ after irradiation, showing no significant differences compared to those before irradiation. The range of concentrations might be attributed to measuring errors of digital glucometer.

When irradiated with $15.370 \mathrm{GHz}$ microwaves, Group DC showed higher fasting serum glucose and lower fasting serum insulin levels compared to Group NC before and $2 \mathrm{~h}$ after irradiation. $2 \mathrm{~h}$ after irradiation, fasting serum glucose levels were significantly decreased in Groups $\mathrm{N}+\mathrm{MW}$ and $\mathrm{D}+\mathrm{MW}$ compared to those before irradiation, but showed no changes in fasting serum insulin levels (see Table 3).

Normal and diabetic rats irradiated with $15.370 \mathrm{GHz}$ microwaves for an hour showed lowered FBG levels lasting for $3 \mathrm{~h}$ and $2 \mathrm{~h}$ respectively (measured at 1 hour interval after the commencement of irradiation), compared with those before irradiation.

When irradiated with $15.370 \mathrm{GHz}$ microwaves, in
Groups DC + GL and DC + GL + MW, BG levels $2 \mathrm{~h}$ after loading were significantly $(\mathrm{P}<0.05, \mathrm{P}<0.01)$ higher compared to those before irradiation, but that of Group DC $+\mathrm{GL}+\mathrm{MW}$ was significantly $(\mathrm{P}<0.05)$ lower than that of Group DC + GL (see Table 4).

After microwave irradiation, rats may be a little uneasy, moving to and from, rubbing their nose, stiffening of hair with tail reaction, etc. We looked for any sign of these behaviors but noticed no adverse effects in case of microwave irradiation for 1 hour at low intensities below $10 \mathrm{~mW} / \mathrm{cm}^{2}$.

\section{Discussion}

The incidence of diabetes mellitus is increasing worldwide, especially in developed countries, and various bioresonance therapies as well as conventional anti-diabetic agents have been used for the treatment (20).

The structural dependent characteristics of the water samples are influenced by microwave irradiation of low intensity. Hence, the distilled water irradiated at the frequency of the microwave corresponding to the human ICF might serve as an information carrier for the treatment of a patient (13).

Some investigators demonstrated that by transferring drug (e.g., amphotericin B and metronidazole) information to water molecules by means of resonant circuit coupled 
to electronic amplifier (bioresonance therapy device, Bicom), the growth of candida and amoeba was remarkably inhibited. They suggested that it is possible to store and transfer biological information to distilled water, and that water samples subjected to such information transfer, could successfully interact with other biological systems $(21,22)$.

In living organisms, most of the biological information is transferred via a carrier like water mentioned above. For example, human insulin molecules could also be considered information carriers. Proinsulin consists of insulin and C-peptide; an initial cleavage by a trypsin-like enzyme followed by several cleavages by a carboxypeptidase-like enzyme results in the production of the heterodimeric insulin molecule and the $\mathrm{C}$-peptide. The $\mathrm{C}$-peptide has no known biological activity. It is a distinct molecule from an antigenic standpoint. Thus, C-peptide immunoassays can distinguish insulin secreted endogenously from insulin administered exogenously and can quantitate the former when anti-insulin antibodies preclude the direct measurement of insulin. The main target tissues of insulin include muscle, connective tissue, adipose tissue and liver (23).

The insulin action begins when it binds to a specific glycoprotein receptor on the surface of the target cell. The insulin receptor has been studied in great detail using biochemical and recombinant DNA techniques. It is a heterodimer consisting of two subunits, designated $\alpha$ and $\beta$, in the configuration $\alpha_{2} \beta_{2}$, linked by disulfide bonds. Each of these glycoprotein subunits has a unique structure and function. The $\alpha$ subunit is entirely extracellular, and it binds insulin, probably via a cysteine-rich domain. The $\beta$ subunit is a transmembrane protein that performs the second major function of a receptor, i.e., signal transduction. The cytoplasmic portion of the $\beta$ subunit has tyrosine kinase activity and an autophosphorylation site. Both of these are thought to be involved in signal transduction and insulin action. When insulin binds to the receptor, the conformational change and cross-link, form of microaggregates of the receptor, and generation of one or more signals occur. The diverse actions of the insulin can occur within seconds or minutes (glucose transport, protein phosphorylation, activation and inhibition of enzymes, RNA synthesis) or after a few hours (protein and DNA synthesis and cell growth) (23).

There might be suspicions whether the insulin molecule should necessarily bind to its receptor for information transmission. According to bioresonance theory, the activation of insulin receptor could be achieved through electromagnetic resonance of the hormone molecule and its receptor, not through their chemical binding with each other. In other words, irradiation of electromagnetic wave at the insulin characteristic frequency, which causes resonance with the target receptor, could exert action effects of the insulin. Therefore, if the characteristic frequency of insulin exerting the hypoglycemic effect is identified, patients with diabetes mellitus could be treated without insulin injection. In some studies $(13,21,22)$, water was used as information carrier, while electromagnetic waves were used in the current study.

Having assumed that insulin's hypoglycemic characteristic frequency would be in microwave band, we identified six peak frequencies in the frequency-intensity curve of insulin, obtained with Network Analyzer. Insulin is a polypeptide consisting of A (21 amino acids) and B (30 amino acids) chains, linked by two disulfide bridges. Besides, it is considered that several regions including the three disulfide bonds, the hydrophobic residues in the carboxyl terminal region of the $\mathrm{B}$ chain, and the amino and carboxyl terminal regions of the A chain are crucial for bioactivity. It seemed to be reasonable that insulin has several peak frequencies as it is a complex molecule that comprises two polypeptide chains each of which also includes a few functional regions. Only one or two among six peak frequencies might have receptor-activating information, the information for hypoglycemic effects.

Among the frequencies, only $15.37 \mathrm{GHz}$ could exert the ability to lower the FBG level and glucose tolerance, especially, $15.370 \mathrm{GHz}$ showed the highest effect. This frequency causes electromagnetic resonance of the insulinbinding domains of $\alpha$ subunits, changing the conformation of receptor, thus leading to lowering of BG level.

$15.370 \mathrm{GHz}$, the frequency obtained from our results, would be the closest to insulin's hypoglycemic characteristic frequency. Microwave irradiation at the frequency had remarkable hypoglycemic effects even in low intensities less than $10 \mathrm{~mW} / \mathrm{cm}^{2}$, resulting in bioresonance therapy relatively independent on the amount of transferred energy unlike other physical therapies. The frequency specificity and low energy requirement suggested that resonance phenomenon underlies the hypoglycemic effect of the microwave.

Microwave irradiation at $15.370 \mathrm{GHz}$ also showed marked hypoglycemic effects in pancreas-resected rats just like in normal rats (data not shown), but did not degrade the glucose in vitro. In addition, the decreased BG levels and unchanged serum insulin levels were observed in normal and STZ-induced diabetic rats. This indicates the microwave 
irradiation at this frequency does not directly stimulate the $\beta$ cells of the islets of Langerhans and decreases the BG level, but indirectly lowers the level in a way in which irradiation of microwave at this frequency would exert additive effects to that of insulin secreted from $\beta$ cells of pancreas. It is considered that the microwave at $15.370 \mathrm{GHz}$ has the "hypoglycemic information", thus is able to transmit the information to insulin receptors.

\section{Conclusions}

This study demonstrates that irradiation of microwave at the frequency of $15.370 \mathrm{GHz}$ with intensities of 0.1 to $10 \mathrm{~mW} / \mathrm{cm}^{2}$ for 1 hour could decrease the FBG and the BG levels after glucose loading in normal rats just like insulin. The hypoglycemic effects of microwave irradiation were also significant in STZ-induced diabetic rats. Normal and diabetic rats irradiated with $15.370 \mathrm{GHz}$ microwaves for an hour showed lowered FBG levels lasting for $3 \mathrm{~h}$ and $2 \mathrm{~h}$ respectively (measured at 1 hour interval after the commencement of irradiation). However, further studies should be made to elucidate the mechanism by which microwave irradiation lowers the BG level, and to develop the therapeutic apparatus. Besides, randomized double blind clinical trials should be undertaken to confirm efficacy of irradiation of microwave among diabetic patients.

\section{Acknowledgments}

We are grateful to Dr. Kim Chol-Song from National Academy of Sciences, DPR Korea, for his technical assistance in identification of resonant frequencies of insulin and its application in animal models. We also thank Dr. Pak Yong-On from National Academy of Sciences, DPR Korea, for his assistance in determining the serum insulin levels by electrochemiluminescence immunoassay method.

Funding: None.

\section{Footnote}

Reporting Checklist: The authors have completed the ARRIVE reporting checklist. Available at http://dx.doi. org/10.21037/ht-20-7

Data Sharing Statement: Available at http://dx.doi. org/10.21037/ht-20-7

Conflicts of Interest: All authors have completed the ICMJE uniform disclosure form (available at http://dx.doi. org/10.21037/ht-20-7). The authors have no conflicts of interest to declare.

Ethical Statement: The authors are accountable for all aspects of the work in ensuring that questions related to the accuracy or integrity of any part of the work are appropriately investigated and resolved. Experiments were performed under a project license (No. 1354822) granted by the University ethics board of the Pyongyang Medical College, in compliance with the University guidelines for the care and use of animals.

Open Access Statement: This is an Open Access article distributed in accordance with the Creative Commons Attribution-NonCommercial-NoDerivs 4.0 International License (CC BY-NC-ND 4.0), which permits the noncommercial replication and distribution of the article with the strict proviso that no changes or edits are made and the original work is properly cited (including links to both the formal publication through the relevant DOI and the license). See: https://creativecommons.org/licenses/by-nc-nd/4.0/.

\section{References}

1. Kumar R, Arora V, Ram V, et al. Hypoglycemic and hypolipidemic effect of Allopolyherbal formulations in streptozotocin induced diabetes mellitus in rats. Internat J Diabetes Mellitus 2015;3:45-50.

2. Baroni S, da Rocha BA, Oliveira de Melo J, et al. Hydroethanolic extract of Smallanthus sonchifolius leaves improves hyperglycemia of streptozotocin induced neonatal diabetic rats. Asian Pac J Trop Med 2016;9:432-6.

3. Hassan SK, Mohammed El-Sammad N, Mousa AM, et al. Hypoglycemic and antioxidant activities of Caesalpinia ferrea Martius leaf extract in streptozotocin-induced diabetic rats. Asian Pac J Trop Biomed 2015;5:462-71.

4. Kameswara Rao B, Renuka Sudarshan P, Rajasekhar $M D$, et al. Antidiabetic activity of Terminalia pallida fruit in alloxan induced diabetic rats. J Ethnopharmacol 2003;85:169-72.

5. Rajalakshmi M, Anita R. $\beta$-cell regenerative efficacy of a polysaccharide isolated from methanolic extract of Tinospora cordifolia stem on streptozotocin -induced diabetic Wistar rats. Chem Biol Interact 2016;243:45-53.

6. Islamov BI, Balabanova RM, Funtikov VA, et al. Effect of bioresonance therapy on antioxidant system in lymphocytes in patients with rheumatoid arthritis. Bull 
Exp Biol Med 2002;134:248-50.

7. Schäfer T. Epidemiology of complementary alternative medicine for asthma and allergy in Europe and Germany. Ann Allergy Asthma Immunol 2004;93:S5-10.

8. Worm M, Henz BM. Novel unconventional therapeutic approaches to atopic eczema. Dermatology 2000;201:191-5.

9. Jia DZ, Li G. Bioresonance hypothesis: a new mechanism on the pathogenesis of trigeminal neuralgia. Med Hypotheses 2010;74:505-7.

10. Fedorowski A, Steciwko A, Rabczyński J. Serum cathepsin $\mathrm{B}$ activity during regression of Morris hepatoma $5123 \mathrm{D}$. Med Sci Monit 2004;10:BR144-50.

11. Lysenyuk VP, Samosyuk IZ, Kulikovich YN, et al. Experimental study on the low-intensity millimeterwave electromagnetic stimulation of acupuncture points. Acupunct Electrother Res 2000;25:91-9.

12. Shaklein AV, Bogatova NP, Kuleshov VM, et al. Morphological criteria for normalization of menstrual function in women with spontaneous abortion. Bull Exp Biol Med 2002;134:505-8.

13. Emelyanov VA, Klimenko PD, Baranov VV, et al. Use of bio-resonance effects for medical diagnostics and therapy. Rome: 2009 European Microwave Conference (EuMC), 2009:1591-4.

14. Elberry AA, Harraz FM, Ghareib SA, et al. Methanolic extract of Marrubium vulgare ameliorates hyperglycemia and dyslipidemia in streptozotocin-induced diabetic rats. Internat J Diabetes Mellitus 2015;3:37-44.

15. Tanko Y, Yerima M, Mahdi MA, et al. Hypoglycemic

doi: $10.21037 / \mathrm{ht}-20-7$

Cite this article as: Ryo JS, Jo GR, Kim GS, Ri JA. Frequencyspecific hypoglycemic effects of microwave irradiation on normal and streptozotocin-induced diabetic rats. Health Technol 2021;5:3. activity of methanolic stem bark of Adansonia digitata extract on blood glucose levels of streptozocin-induced diabetic Wistar rats. Int J Appl Res Nat Prod 2008;1:32-6.

16. Beach EF, Turner JJ. An enzymatic method for glucose determination in body fluids. Clin Chem 1958;4:462-75.

17. Rheney CC, Kirk JK. Performance of three blood glucose meters. Ann Pharmacother 2000;34:317-21.

18. Sapin R, Le Galudec V, Gasser F, et al. Elecsys insulin assay: free insulin determination and the absence of crossreactivity with insulin lispro. Clin Chem 2001;47:602-5.

19. Abdul-Hamid M, Moustafa N. Protective effect of curcumin on histopathology and ultrastructure of pancreas in the alloxan treated rats for induction of diabetes. J Basic \& Appl Zool 2013;66:169-79.

20. Mohammed A, Adelaiye AB, Abubakar MS, et al. Effects of aqueous extract of Ganoderma lucidum on blood glucose levels of normoglycemic and alloxan-induced diabetic wistar rats. J Medicin Plants Res 2007;1:34-7.

21. Heredia-Rojas JA, Torres-Flores AC, Rodríguez-De la Fuente AO, et al. Entamoeba histolytica and Trichomonas vaginalis: trophozoite growth inhibition by metronidazole electro-transferred water. Exp Parasitol 2011;127:80-3.

22. Heredia-Rojas JA, Gomez-Flores R, Rodríguez-De la Fuente AO, et al. Antimicrobial effect of amphotericin B electronically-activated water against Candida albicans. Afric J Microbiol Res 2012;6:3684-9.

23. Nelson DL, Cox MM. Lehninger Principles of Biochemistry. New York: W. H. Freeman and Company, 2008. 